\title{
Cardiac metastases from primary myxoid liposarcoma of the thigh: a case report
}

\author{
Kunihiro Ikuta ${ }^{1,2^{*}} \mathbb{D}$, Tomohisa Sakai ${ }^{1}$, Hiroshi Koike', Tohru Okada ${ }^{3}$, Shiro Imagama ${ }^{1}$ and Yoshihiro Nishida ${ }^{1,4}$
}

\begin{abstract}
Background: Myxoid liposarcoma is well known to have an unusual proclivity for extrapulmonary metastasis. However, cardiac metastasis of myxoid liposarcoma is very rare, even in patients with advanced disease.

Case presentation: A 40-year-old man was diagnosed with myxoid liposarcoma of the right thigh and treated with wide resection. Two years after the surgery, a low-density area in the left ventricle was found on follow-up chest computed tomography, and was suspected of being metastatic disease. He underwent surgical treatment, and the lesion was pathologically confirmed as metastasis of myxoid liposarcoma. Fifteen months later, he complained of slight dyspnea and developed metastatic disease in the right atrium. He was treated with surgical excision, followed by radiotherapy. Although there was no recurrence in the heart since the second cardiac metastasectomy, multiple metastases occurred in the abdominal cavity, lungs, and muscles. He finally died of the disease 2 years after the second cardiac metastasectomy.

Conclusion: We experienced a case of primary myxoid liposarcoma in the thigh, accompanied by ectopic and metachronous cardiac metastases. Although this condition is rare, we should follow-up patients with myxoid liposarcoma, considering the possibility of cardiac metastasis.
\end{abstract}

Keywords: Cardiac metastasis, Myxoid liposarcoma, Extrapulmonary metastasis

\section{Background}

Myxoid liposarcoma (MLS) is the second most common subtype of liposarcoma arising in children, adolescents, and young adults [1]. MLS usually occurs in deep tissues of the extremity, especially in the thigh. Some tumors have round cell areas that represent histologic progression to high-grade tumors. Round cells, defined as greater than $5 \%$ of the total cells, are associated with higher malignancy and metastatic potential, resulting in an unfavorable outcome in patients with MLS [2,3].

MLS is known as a translocation-related sarcoma and has a translocation with FUS-DDIT3 or rarely EWSR1-

\footnotetext{
* Correspondence: k-ikuta@med.nagoya-u.ac.jp

'Department of Orthopaedic Surgery, Nagoya University Graduate School and School of Medicine, 65 Tsurumai, Showa, Nagoya 466-8550, Japan

${ }^{2}$ Medical Genomics Center, Nagoya University Hospital, 65 Tsurumai, Showa, Nagoya 466-8550, Japan

Full list of author information is available at the end of the article
}

DDIT3 fusion. Since the fusion protein resulting from these fusion genes acts as activated and deregulated transcriptional factors, it stimulates the proliferation of tumor cells [4]. Approximately one third of patients with MLS develop distant metastatic spread [5, 6]. Patients with MLS tend to have metastases to extrapulmonary sites, such as retroperitoneum, abdominal wall, abdominal cavity, and bone, even in the absence of pulmonary metastases $[2,7]$. Although several authors have reported a high proportion of extrapulmonary metastases of MLS, ranging from 50 to $78 \%$ of all metastases [7-10], cardiac metastasis is extremely rare. Here we present a case of cardiac metastasis that occurred in a patient with primary MLS of the thigh.

\section{Case presentation}

A 40-year-old man with a history of MLS in the right thigh was treated with wide excision at our hospital 

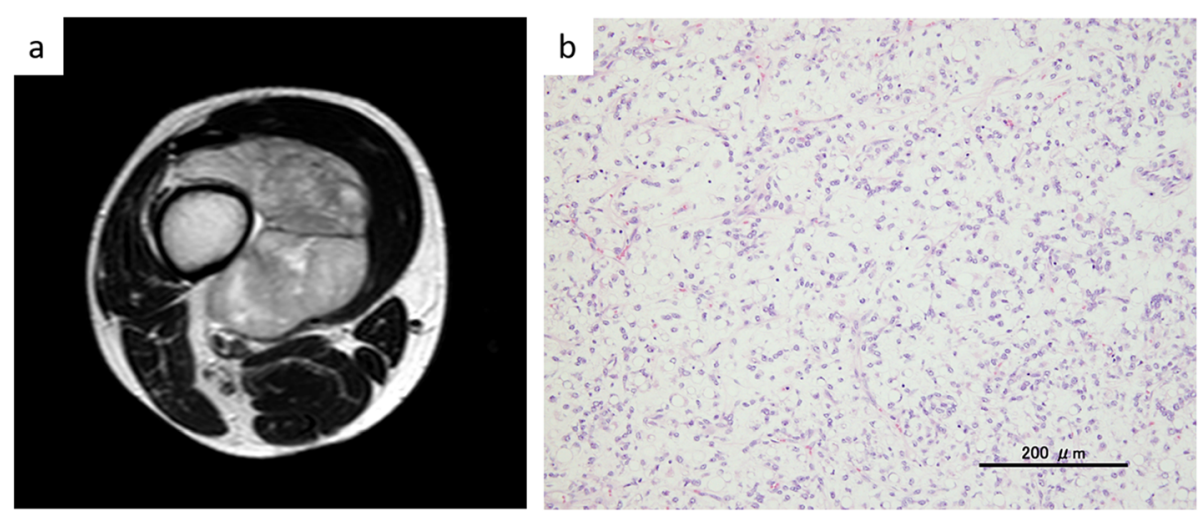

Fig. 1 The findings at the initial diagnosis. a Axial T2-weighted MRI of primary myxoid liposarcoma of the right thigh showed a hyperintense mass adjacent to the distal femur. $\mathbf{b}$ The histological findings of the specimen in the resected primary tumor of the right thigh (hematoxylin and eosin, original magnification, $\times 200$ ). A mixture of uniform oval non-lipogenic cells and small signet ring lipoblasts in a prominent myxoid stroma were observed

(Fig. 1a). At the time of diagnosis, he had no distant metastasis. Histological findings of the resected specimen revealed a round cell component of $10 \%$ and a negative margin (Fig. 1b). Adjuvant chemotherapy with four cycles of doxorubicin $\left(70 \mathrm{mg} / \mathrm{m}^{2}\right.$, every 3 weeks) was administered.
Two years after the surgery for the primary tumor, follow-up chest computed tomography (CT) showed a low-density area in the left ventricle. The patient was then asymptomatic. Contrast-enhanced CT showed a mass, measuring $4 \mathrm{~cm} \times 2 \mathrm{~cm}$ in the left ventricle (Fig. 2a). Transthoracic echocardiography also identified the mass
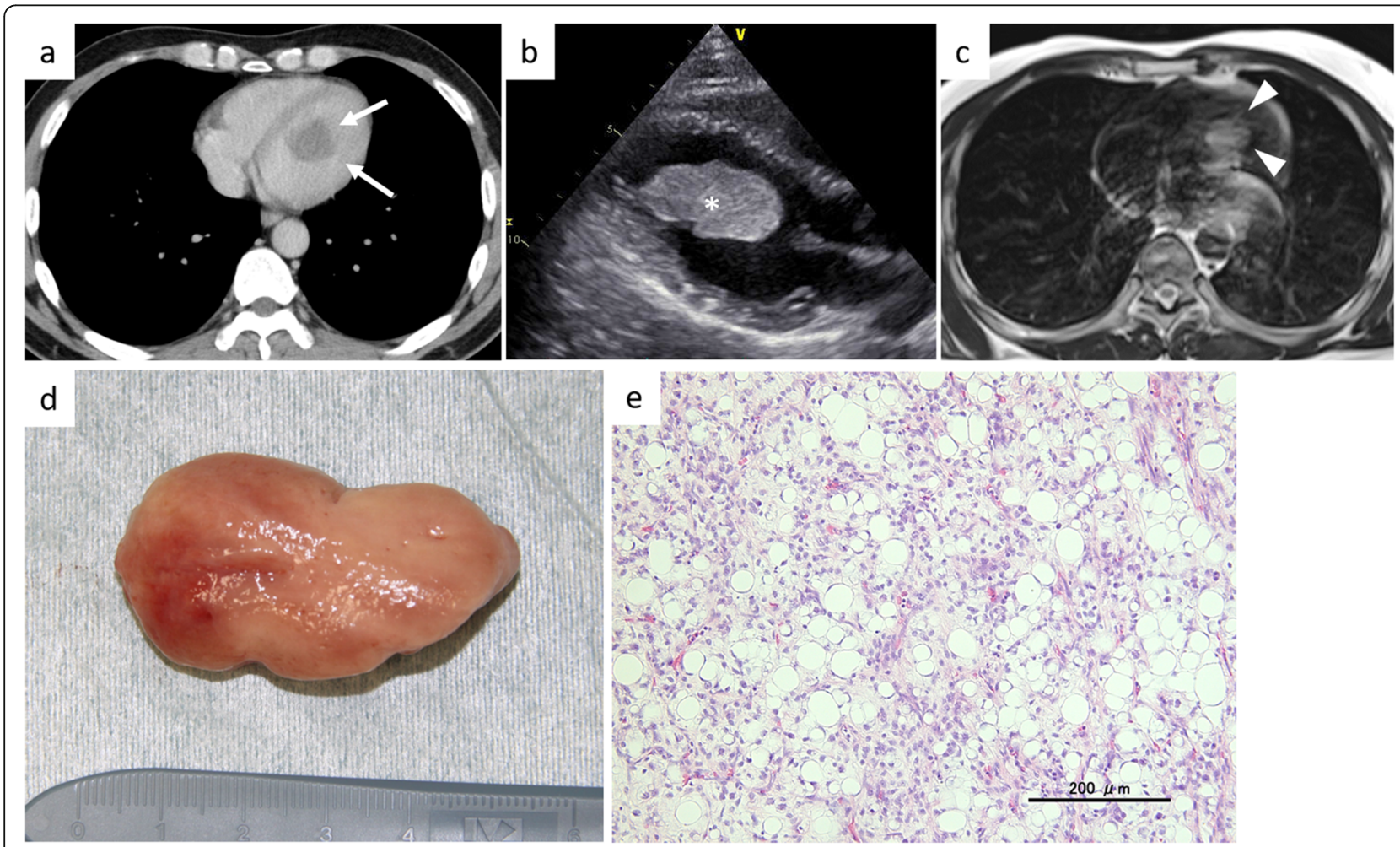

Fig. 2 The findings at the first cardiac metastasis. a Chest CT scan showed a low-density lesion in the left ventricle (arrows). b Transthoracic echocardiography depicted a left ventricular mass, measuring $4 \mathrm{~cm} \times 2 \mathrm{~cm}$ (asterisk). c Axial T2-weighted MRI demonstrated a high-signal intensity area compared to skeletal muscle within the mass (arrowheads). $\mathbf{d}$ Surgical material of the left ventricular tumor. e Photomicrograph of the resected specimen in the left ventricle showed increased areas of round cell component, compatible with metastasis of myxoid liposarcoma (hematoxylin and eosin, original magnification, $\times 200$ ) 
in the left ventricle, which was suggestive of a neoplasm (Fig. 2b). Clinical images revealed no evidence of local recurrence or distant metastasis other than the cardiac mass at that time. Given the risk of valve obstruction, he was immediately admitted to our hospital for cardiovascular surgery. On magnetic resonance imaging (MRI), the left ventricular tumor showed a lower-signal intensity than that of skeletal muscle on T1-weighted images, highersignal intensity on T2-weighted images, and slight enhancement with a contrast agent (Fig. 2c). Considering the clinical course, the mass was regarded as a metastasis of MLS. He underwent surgical excision of the lesion in the left ventricle. Intraoperatively, we found a reddishwhite tumor (Fig. 2d) arising from the papillary muscle without invasion of the interventricular septum. Histopathological examination of the specimen showed a mixture of oval non-lipogenic cells and small signet ring lipoblasts in a prominent myxoid stroma, which was consistent with the findings of the primary tumor in the thigh. However, the proportion of round cell component in the ventricular specimen was increased compared with that in the specimen of the primary tumor (Fig. 2e). A negative margin was histologically confirmed in the ventricular specimen.

Six months later, he complained of back pain and developed metastatic disease in the sixth thoracic vertebra.
Conventional radiotherapy was administered to the spine lesion, which was delivered as 50 Gy in 25 fractions.

Fifteen months after the cardiac metastasectomy, he presented slight dyspnea on effort. Contrast-enhanced CT showed a tumor in the right atrium involving the atrium septum (Fig. 3a). Our cardiovascular surgeons decided that the lesion was not amenable to complete excision with an adequate margin. The patient was treated with surgical excision of the tumor with R2 margin (macroscopically evident margin positivity) (Fig. 3b). The histological findings of the specimen indicated MLS with hypercellular lesions with a round cell component of about $30 \%$, which represented progression compared to that of the left ventricular specimen at the first cardiac metastasectomy (Fig. 3c). Radiotherapy of 50 Gy in 25 fractions was performed for the residual disease of the right atrium and atrial septum postoperatively. His ejection fraction evaluated with echocardiography after the second cardiac metastasectomy remained $40 \%$, and he could perform his daily activities without difficulty. There was no recurrence in the heart after the second cardiac metastasectomy, although multiple metastases occurred in the abdominal cavity, lungs, and muscles. Despite palliative chemotherapy with trabectedin and eribulin, he finally died of the disease 2 years after the second cardiac metastasectomy.

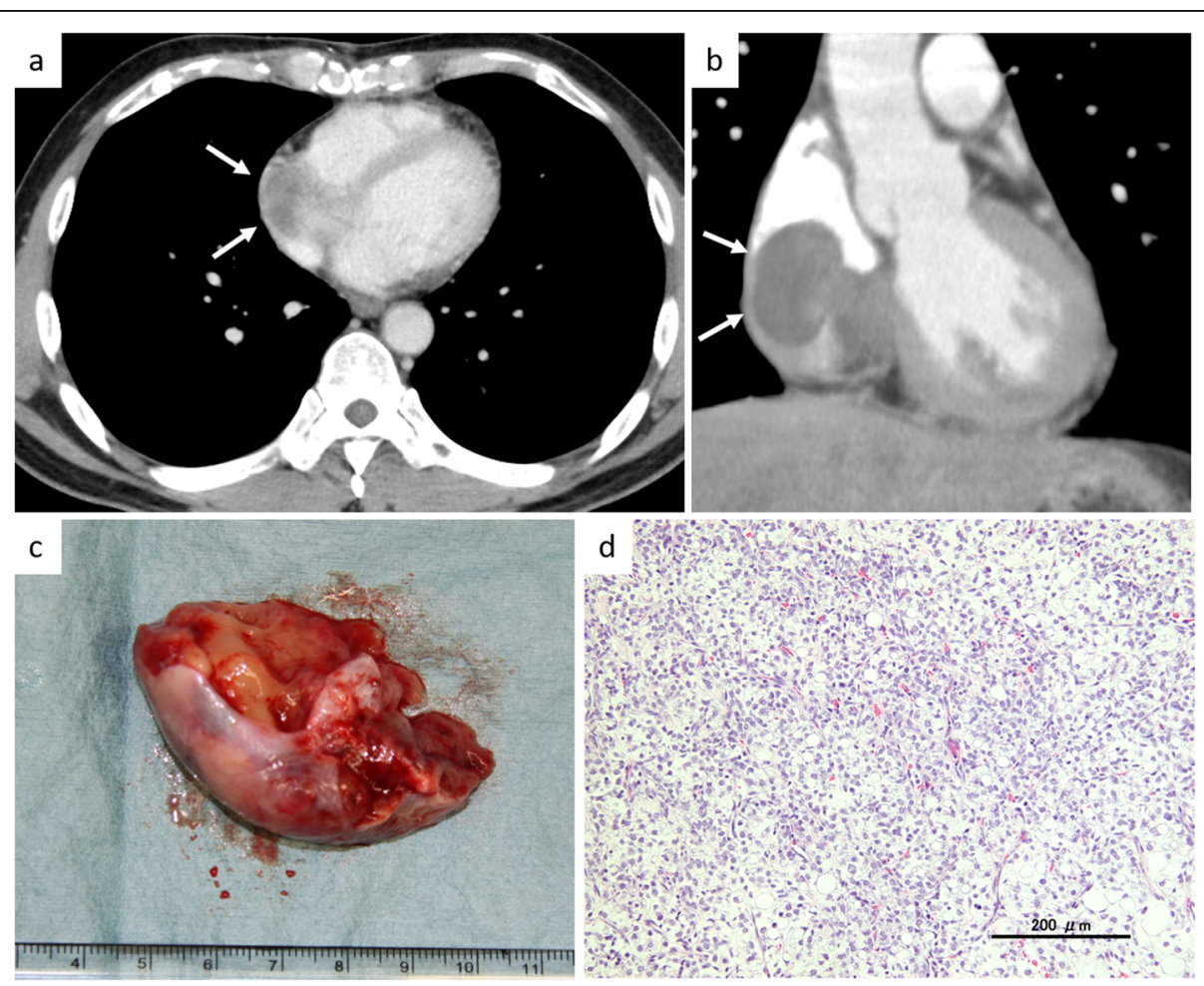

Fig. 3 The findings at the second cardiac metastasis. a Axial and $\mathbf{b}$ coronal views of contrast-enhanced CT showed a metastatic tumor located in the right atrium (arrows). $\mathbf{c}$ The partially resected specimen from the atrial septum. $\mathbf{d}$ Photomicrograph of the resected specimen demonstrated hypercellular areas with round cell morphology (hematoxylin and eosin, original magnification, $\times 200$ ) 


\section{Discussion and conclusions}

Although cardiac metastasis from soft tissue sarcomas has been mentioned in the literature [11-19], early diagnosis of cardiac metastasis from soft tissue sarcomas is difficult for musculoskeletal oncologists because of its rarity. As to MLS, approximately thirty cases with metastasis to the heart, including pericardium, have been reported so far (Table 1). Most of these patients had disseminated disease. The time intervals between the onset of primary disease and cardiac metastasis were reported to be relatively long, ranging from 1 to 25 years [15-20]. The initial site of metastatic disease in our patient was the heart. He had a solitary cardiac tumor without obvious symptoms that presented 2 years after the primary surgery in the absence of metastases at other sites. Only $10 \%$ of patients with cardiac metastasis have been reported to show any symptoms [11]. This made it difficult to recognize the possibility of cardiac metastasis in our patient. On the other hand, he presented with slight dyspnea on exertion at the diagnosis of the second cardiac metastasis, probably because of inflow tract obstruction in the right atrium. Clinical symptoms depend on the location and extent of the lesion, which variously affect cardiac function. Careful physical examination alone is not sufficient for the early diagnosis of cardiac metastasis.

The lung is the most carefully monitored organ for the development of metastases in soft tissue sarcomas. However, pulmonary metastases often occur with a time lag behind extrapulmonary metastases in patients with MLS. Estourgie et al. reported that 55\% of MLS patients with metastatic disease had extrapulmonary metastases [7]. Nishida et al. noted that $50 \%$ of metastases occurred in extrapulmonary sites, even in MLS patients with round cell components of less than 5\% [10]. The tendency to metastatic spread in extrapulmonary sites was attributed to an affinity for adipose tissues such as those in the retroperitoneum, subcutaneous tissues, and bone marrow

Table 1 Cases with cardiac metastasis of myxoid liposarcoma in the previous literature

\begin{tabular}{|c|c|c|c|c|c|c|}
\hline Author & Year & Age & Gender & Symptom & Metastatic sites & Interval (years) \\
\hline Tong et al. & 1968 & 35 & M & Dyspnea & LV & 7 \\
\hline Godwin et al. & 1981 & 59 & M & Systolic murmur & $\mathrm{RV}$, pericardium & 25 \\
\hline Ravikumar et al. & 1983 & 76 & M & $\mathrm{CHF}$ & $\mathrm{LV}$, pericardium & 25 \\
\hline Lagrange et al. & 1986 & 46 & F & $\mathrm{CHF}$ & $\mathrm{RV}$ & 7 \\
\hline Bartels et al. & 1988 & 64 & $M$ & $\mathrm{CHF}$ & $\mathrm{RV}$ & 3 \\
\hline Ozoux et al. & 1988 & 60 & $M$ & Murmur & LV & 17 \\
\hline Oshima et al. & 1993 & 37 & M & Not described & LV & 5 \\
\hline Papa et al. & 1994 & 45 & M & Dyspnea & LV & 15 \\
\hline Hatton et al. & 1997 & 39 & $M$ & Angina & Pericardium & 4.5 \\
\hline Sugiyama et al. & 2000 & 61 & $\mathrm{~F}$ & $\mathrm{CHF}$ & $\mathrm{RV}$ & 11 \\
\hline $\mathrm{Ng}$ et al. & 2001 & 45 & $M$ & Arrhythmia & Interventricular septum & 3 \\
\hline Lee et al. & 2002 & 53 & $\mathrm{~F}$ & $\mathrm{CHF}$ & Pericardium & 5 \\
\hline Wong et al. & 2002 & 54 & M & Dyspnea & RV & 7 \\
\hline Fairman et al. & 2004 & 56 & $\mathrm{~F}$ & Angina, syncope & LV & 12 \\
\hline Kono et al. & 2005 & 60 & M & SVC syndrome & SVC, RA, RV & 13 \\
\hline Aoyama et al. & 2005 & 63 & $\mathrm{~F}$ & Dyspnea & Pericardium & 1 \\
\hline Komoda et al. & 2009 & 52 & M & Dyspnea & RA, RV, arterio-ventricular sulcus & 17 \\
\hline Lazopoulos et al. & 2011 & 63 & M & $\mathrm{CHF}$ & LV, pericardium, interventricular septum & 13 \\
\hline Markovic et al. & 2012 & 45 & $\mathrm{~F}$ & Angina & Pericardium & 5 \\
\hline Fernández-Golfín et al. & 2012 & 68 & M & Not described & Pericardium & Not described \\
\hline Pino et al.* & 2013 & - & - & - & - & - \\
\hline Mottahedi et al. & 2013 & 50 & $\mathrm{~F}$ & Dyspnea & RA, RV & 4 \\
\hline Virtová et al. & 2014 & 36 & $M$ & No symptoms & Interventricular septum & 5 \\
\hline Xu et al. & 2014 & 60 & $M$ & Dyspnea & $\mathrm{RV}$ & 20 \\
\hline Farmer et al. & 2014 & 61 & $M$ & $\mathrm{CHF}$ & LV & 17 \\
\hline Motevalli et al. & 2017 & 46 & M & Dyspnea & LV, PA, pericardium & 16 \\
\hline
\end{tabular}

$M$ male, $F$ female, $C H F$ congestive heart failure, $R A$ right atrium, $R V$ right ventricle, $L V$ left ventricle, $P A$ pulmonary artery, $S V C$ superior vena cava ${ }^{*}$ Case series 
[5]. If physicians depend on imaging of the chest and primary site as the initial staging and follow-up studies, a significant number of metastases may be missed due to the high incidence of extrapulmonary metastases in patients with MLS [21]. For the staging of MLS at diagnosis, the 2017 National Comprehensive Cancer Network $(\mathrm{NCCN})$ guidelines recommended chest imaging and abdominal/pelvic CT as well as total spine MRI [22]. Recent studies suggest that whole-body MRI is the most reliable modality for surveillance of all likely sites of extrapulmonary metastases $[6,23]$. Although our patient underwent chest CT and thigh MRI every 3-4 months and annual total spine MRI after surgery for the primary tumor, he did not received a follow-up with whole-body MRI.

Positron emission tomography is used as an alternative imaging modality to screen for metastases in patients with malignancies. However, metastatic lesions of MLS are likely to have low uptake on positron emission tomography [6]. False-negative results of positron emission tomography in patients with MLS have been widely documented, with a reported sensitivity as low as $14 \%$ for the detection of spinal metastases [21].

When a cardiac metastasis is found incidentally, it is usually incurable. In our patient, the disease in the right atrium was not a recurrence of the first cardiac metastasis in the left ventricle but was considered a metachronous metastatic lesion. Surgical treatment may not be the best option for patients with cardiac metastasis. However, in selected patients with no evidence of distant metastases, surgical excision of the cardiac metastasis, if technically feasible, provides a chance to prolong survival in life-threatening situations such as mechanical obstruction or valvular dysfunction $[18,19]$. If the surgical margin is positive after cardiac metastasectomy, radiotherapy can be useful as a supplemental procedure since MLS is regarded to be radiosensitive. Although surgery is the mainstay of treatment for localized MLS, systemic therapy is often given to patients with locally advanced or metastatic MLS. Currently, doxorubicin, eribulin, and trabectedin are being used widely with some success in patients with advanced MLS.

To summarize, this report described a patient with MLS in the thigh, accompanied by ectopic and metachronous cardiac metastases. Periodic examinations with chest CT with careful attention may be able to document the presence of cardiac disease before the occurrence of severe cardiac complications. In patients with a solitary cardiac metastasis, especially when detected at an early stage, surgical excision, followed by some adjuvant therapies, can be the treatment of choice.

\section{Abbreviations}

MLS: Myxoid liposarcoma; CT: Computed tomography; MRI: Magnetic resonance imaging

\section{Acknowledgements}

The authors thank Akihiko Usui and Sachie Terazawa, cardiovascular surgeons of Nagoya University Hospital, for the surgical procedures and clinical support.

\section{Authors' contributions}

$\mathrm{KI}$ was responsible for the design and drafting of the manuscript and for the concept. SI and YN were responsible for the revision of the manuscript and supervision. TS and HK were responsible for the treatment of the soft tissue sarcoma. TO was responsible for the radiotherapy of the cardiac metastasis. All authors read and approved the final manuscript.

\section{Funding}

The author (KI) has received research funding from the Ministry of Education, Culture, Sports, Science and Technology of Japan [Grant-in-Aid 19K16769 for Young Scientists]

\section{Availability of data and materials}

All data generated or analyzed during this study are included in this published article.

\section{Ethics approval and consent to participate}

A copy of the written consent is available for review by the Editor-in-Chief of this journal.

\section{Consent for publication}

Written informed consent was obtained from the patient for publication of this case report and accompanying images.

\section{Competing interests}

The authors declare that they have no competing interests.

\section{Author details}

'Department of Orthopaedic Surgery, Nagoya University Graduate School and School of Medicine, 65 Tsurumai, Showa, Nagoya 466-8550, Japan.

${ }^{2}$ Medical Genomics Center, Nagoya University Hospital, 65 Tsurumai, Showa, Nagoya 466-8550, Japan. ${ }^{3}$ Department of Radiology, Japanese Red Cross Nagoya Daiichi Hospital, 3-35, Michishita, Nakamura, Nagoya 453-8511, Japan. ${ }^{4}$ Department of Rehabilitation, Nagoya University Hospital, 65 Tsurumai, Showa, Nagoya 466-8550, Japan.

Received: 22 July 2020 Accepted: 20 August 2020

Published online: 27 August 2020

\section{References}

1. Alaggio R, Coffin CM, Weiss SW, Bridge JA, Issakov J, Oliveira AM. Liposarcomas in young patients: a study of 82 cases occurring in patients younger than 22 years of age. Am J Surg Pathol. 2009;33:645-8.

2. Spillane AJ, Fisher C, Thomas JM. Myxoid liposarcoma - the frequency and the natural history of nonpulmonary soft tissue metastases. Ann Surg Oncol. 1999;6:389-94.

3. Dei Tos AP. Liposarcomas: diagnostic pitfalls and new insights. Histopathology. 2014;64:38-52.

4. Turpin A, Taieb S, Penel N. Tumor calcification: a new response pattern of myxoid liposarcoma to trabectedin. Case Rep Oncol. 2014;7:204-9.

5. Ogose A, Hotta T, Inoue Y, Sakata S, Takano R, Yamamura S. Myxoid liposarcoma metastatic to the thoracic epidural space without bone involvement: report of two cases. Jpn J Clin Oncol. 2001;31:447-9.

6. Schwab JH, Boland P, Guo T, Brennan MF, Singer S, Healey JH, et al. Skeletal metastases in myxoid liposarcoma: an unusual pattern of distant spread. Ann Surg Oncol. 2007;14:1507-14.

7. Estourgie SH, Nielsen GP, Ott MJ. Metastatic patterns of extremity myxoid liposarcoma and their outcome. J Surg Oncol. 2002;80:89-93.

8. Muratori F, Bettini L, Frenos F, Mondanelli N, Greto D, Livi L, et al. Myxoid liposarcoma : prognostic factors and metastatic pattern in a series of 148 patients treated at a single institution. Int J Surg Oncol. 2018;8928706. https://doi.org/10.1155/2018/8928706.

9. Guadagnolo BA, Zagars GK, Ballo MT, Patel SR, Lewis VO, Benjamin RS, et al. Excellent local control rates and distinctive patterns of failure in myxoid liposarcoma treated with conservation surgery and radiotherapy. Int J Radiat Oncol Biol Phys. 2008;70:760-5. 
10. Nishida Y, Tsukushi S, Nakashima H, Ishiguro N. Clinicopathologic prognostic factors of pure myxoid liposarcoma of the extremities and trunk wall. Clin Orthop Relat Res. 2010;468:3041-6.

11. Xu G, Shi X, Shao G. An unusual case of metastasis of a pulmonary undifferentiated pleomorphic sarcoma to the right ventricle: a case report. J Med Case Rep. 2013;7:4-8.

12. Oylumlu M, Yildiz A, Ercan S, Oylumlu M, Davutoglu V. Cardiac metastasis of a low-grade myofibroblastic sarcoma. Echocardiography. 2014;31:1-4.

13. Chen Z, Sun C, Sheng W, Yuan B, Wu K, Tian Y, et al. Alveolar soft-part sarcoma in the left forearm with cardiac metastasis: a case report and literature review. Oncol Lett. 2016;11:81-4.

14. Özyüncü N, Turan N, Gerede DM, Özçınar E, Güleç S, Perçinel S, et al. Cardiac metastasis of synovial sarcoma presenting with superior vena cava syndrome. Anatol J Cardiol. 2016;16:E11.

15. Farmer RP, Schowinsky JT, Lindeque BGP. Myxoid liposarcoma of the thigh with metastasis to the left ventricle of the heart. JBJS Case Connect. 2015;5:e91.

16. Ng C, Stebbing J, Judson I. Cardiac metastasis from a myxoid liposarcoma. Clin Oncol. 2001;13:384-5.

17. Wong SP, Ng CS, Wan S, Lee TW, Wan IY, Yim AP, et al. Giant metastatic myxoid liposarcoma causing cardiac tamponade: a case report. Jpn I Clin Oncol. 2002;32:480-2.

18. Motevalli D, Tavangar SM. Extensive left ventricular, pulmonary artery, and pericardial metastasis from myxoid liposarcoma 16 years after the initial detection of the primary tumour: a case report and review of the literature. Malays J Pathol. 2017;39:201-5.

19. Pino PG, Zampi G, Pergolini G, Pero G, Plizzi V, Sbaraglia F, et al. Metastatic liposarcoma of the heart. Case series and brief literature review. Herz. 2013; 38:938-42.

20. Aoyama A, Isowa N, Chihara K, Ito T. Pericardial metastasis of myxoid liposarcoma causing cardiac tamponade. Jpn J Thorac Cardiovasc Surg. 2005;53:193-5

21. Schwab JH, Boland PJ, Antonescu C, Bilsky MH, Healey JH. Spinal metastases from myxoid liposarcoma warrant screening with magnetic resonance imaging. Cancer. 2007;110:1815-22.

22. National Comprehensive Cancer Network. NCCN clinical practice huidelines in oncology (NCCN Guidelines ${ }^{\oplus}$ ). Soft Tissue Sarcoma (Version 2.2017).

23. Gorelik N, Reddy SMV, Turcotte RE, Goulding K, Jung S, Alcindor T, et al. Early detection of metastases using whole-body MRI for initial staging and routine follow-up of myxoid liposarcoma. Skelet Radiol. 2018;47:369-79.

\section{Publisher's Note}

Springer Nature remains neutral with regard to jurisdictional claims in published maps and institutional affiliations.

Ready to submit your research? Choose BMC and benefit from:

- fast, convenient online submission

- thorough peer review by experienced researchers in your field

- rapid publication on acceptance

- support for research data, including large and complex data types

- gold Open Access which fosters wider collaboration and increased citations

- maximum visibility for your research: over $100 \mathrm{M}$ website views per year

At BMC, research is always in progress.

Learn more biomedcentral.com/submissions 